\title{
PROCESO MIGRATORIO, CONCENTRACIÓN ESCOLAR Y RESULTADOS ACADÉMICOS EN CATALUÑA*
}

\section{MIGRATORY PROCESS, SCHOOL CONCENTRATION AND ACADEMIC RESULTS IN CATALONIA}

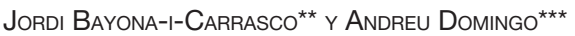

Resumen: La concentración del alumnado inmigrante en las escuelas es vista con preocupación, ya que se relaciona generalmente con una mayor incidencia del fracaso escolar. En este contexto, y para Cataluña, se analiza la relación entre proceso migratorio, concentración escolar y resultados escolares para los alumnos que finalizan la educación secundaria obligatoria. Se emplea una perspectiva generacional, construida a partir del año de llegada a Cataluña, del lugar de origen y del de sus progenitores. Estos datos provienen del enlace realizado por el Instituto de Estadística de Cataluña entre los microdatos de los alumnos matriculados en escuelas públicas en el curso 2015-2016 y el Registro Estadístico de Población. Los resultados indican como la concentración se relaciona, para la mayoría de orígenes, con un incremento del fracaso escolar. Estos efectos se visibilizan a partir de elevados niveles de concentración, y son ambiguos en algunos orígenes, ya que no

* Este trabajo se enmarca en el proyecto de I+D dirigido por Andreu Domingo "Demografía, migraciones y nuevas fronteras estadísticas: Big Data, Registros continuos de población y Registros administrativos” (CSO2017-85670-R), y del proyecto "Inmigración extranjera, concentración territorial y efecto barrio en España”, financiado con una Beca Leonardo para Investigadores y creadores culturales, de la Fundación BBVA, dirigido por Jordi Bayona.

** Centre d'Estudis Demogràfics/CERCA y Departament de Geografia de la Universitat de Barcelona jbayona@ced.uab.es

*** Centre d'Estudis Demogràfics/CERCA adomingo@ced.uab.es 
siempre se producen en el mismo sentido. Adicionalmente, estos efectos son más importantes para los alumnos autóctonos. La elevada diversidad de situaciones sugiere que la relación entre concentración y fracaso escolar no puede ser abordada desde una sola acción política.

Palabras clave: escuela; inmigración; concentración; segregación; fracaso escolar; educación secundaria.

Abstract: The concentration of immigrant students in public schools has raised many concerns, as it is generally related to higher incidence of school failure. In this context, we have analysed the relationship between migration process, concentration of immigrant children in schools and school failure for students who have completed compulsory secondary education in Catalonia. We have used a typology that classifies them according to their migratory status. This analysis is carried out by using the student's year of arrival in Catalonia, their place of origin and that of their parents. The data for this study is provided by the Statistical Institute of Catalonia by linking microdata of students enrolled in public schools of Catalonia, in 2015-2016 academic year, and the Population Statistical Register. The results show that high concentration contributes to an increase in school failure, for most origins, although in some cases the effects are visible from high levels of concentration, but not always in the same sense. Furthermore, these effects are more important for native students than among immigrant categories. The high diversity of situations identified suggests that the relationship between school concentration and failure cannot be addressed with a single policy.

Key words: school; immigration; school soncentration; school segregation; school failure; secondary school.

\section{INTRODUCCIÓN}

El objetivo de este trabajo es el de dilucidar los efectos de la concentración de alumnos de origen inmigrante en la escuela sobre la obtención del Graduado de ESO, o lo que es lo mismo, sobre lo que se denomina éxito o fracaso escolar. En los últimos años ha crecido de notablemente el número de alumnos inmigrados o hijos de inmigrados en España (Carrasco, 2011; Aparicio y Portes, 2014; Portes et al. 2016; González-Ferrer y Cebolla-Boado, 2018), fruto de 
la maduración del proceso migratorio internacional. En el caso que aquí se analiza, el de la escuela catalana, este colectivo de alumnos representa actualmente más de una cuarta parte del total de los escolares matriculados en enseñanzas no universitarias, con una fuerte diferenciación en su distribución territorial y por titularidad del centro escolar, pero también por etapa educativa. El interés en el estudio de los resultados escolares radica en que este análisis nos informará sobre cómo se está desarrollando el proceso de inserción de los menores de origen inmigrante en la sociedad de acogida, y de si existe un efecto concentración, por el cual los alumnos que estudian en centros con un mayor número de alumnos foráneos experimentan resultados negativos. A diferencia de otros trabajos con objetivos similares, el estudio que aquí se propone es de carácter exhaustivo, siendo esto posible por disponer de los microdatos de los alumnos matriculados en el curso 2015-2016 en Cataluña. Así, por primera vez se examinan de forma íntegra los niveles de concentración territorial, que se relacionan con las cifras del fracaso escolar, aunque esta última operación solo la podemos realizar para los alumnos que se encuentran estudiando en escuelas públicas. Al mismo tiempo, este análisis se erige también en un claro ejemplo de una práctica en alza, la utilización de registros administrativos en la investigación social, y de las posibilidades de profundización analítica que aporta el enlace de estos datos con las estadísticas clásicas, como el Padrón continuo de población.

Para ello, el artículo se estructura de la siguiente forma: en primer lugar, se aborda el marco teórico y el estado de la cuestión, centrado en la relación entre concentración de alumnos de origen inmigrante y resultados escolares. En segundo lugar, se exponen las características de los datos estadísticos utilizados y la metodología empleada, aspectos especialmente importantes en cuanto se agrupa a los alumnos a partir de una tipología generacional construida considerando la relación del alumno con el fenómeno migratorio. A continuación, se presentan los principales datos descriptivos referentes a la composición del alumnado en Cataluña, para el curso 2015-2016, haciendo hincapié en la concentración en la escuela. El siguiente apartado analizará la relación entre resultados escolares y concentración en la escuela. Primero se observa la relación de lo que se ha clasificado como "estatus migratorio" con los resultados escolares, para posteriormente centrar la atención en el efecto de la concentración, para el conjunto de alumnos y para una selección de 12 orígenes que se 
han trabajado con mayor grado de detalle. Finalmente, se abordan las conclusiones, donde se resumen las principales aportaciones del trabajo y se reflexiona sobre el efecto de la concentración.

\section{MARCO TEÓRICO. INMIGRACIÓN, CONCENTRACIÓN Y ESCUELA}

\subsection{Concentración, segregación y escuela}

El debate sobre los efectos de la concentración y la segregación de los grupos de inmigrantes se remonta a inicios de siglo XX, cuando desde la que se conoce como escuela de Chicago se estudian los migrantes europeos instalados en las principales ciudades norteamericanas (Burgess, 1928). Desde esta perspectiva, donde prima la visión de la segregación y concentración residencial, la segregación sería un hecho natural en la llegada y primera inserción de los inmigrantes, que disminuiría a medida que crece la asimilación en la sociedad de acogida. El interés en el análisis de la situación escolar es posterior, y tiene su origen en las políticas desagregacionistas surgidas en Estados Unidos desde la sentencia judicial de 1954 en contra de la discriminación racial en las escuelas, convirtiéndose la lucha contra la segregación escolar en las décadas siguientes en una cuestión de estado (Coleman et al. 1975).

Segregación y concentración son dos conceptos fuertemente interrelacionados, aunque no indican exactamente lo mismo. Por segregación, en el caso de la escuela, entendemos la desigual distribución entre alumnos de ciertas características (en este caso alumnos inmigrados o descendientes de inmigrados) en las escuelas. Se habla, entonces, de distancia en la distribución y del hecho de compartir o no unos mismos espacios con el resto del alumnado. La segregación es producto directo de la concentración de uno de los grupos, que como resultado produce la desigual distribución en las escuelas, o bien de la salida de otros, generalmente los autóctonos y en particular sus clases más afluentes, en lo que en la literatura especializada se conoce como "white flight".

En el caso de Cataluña, se documenta la existencia de niveles crecientes de segregación residencial, que tiene además un carácter estructural (Nel.lo, 2018) y que se manifiesta preferentemente en las 
zonas urbanas y metropolitanas. Como consecuencia de las dinámicas segregadoras existen zonas vulnerables (Blanco y Nel.lo, 2018), donde se concentra la pobreza y en muchas ocasiones la población inmigrada, aunque son las clases altas quienes experimentan unos niveles de segregación más importantes (Rubiales 2017; Sarasa, Porcel y Lara-Navarro, 2017). En este contexto, la población inmigrante muestra pautas territoriales con niveles de segregación moderados en Cataluña (Domingo y Bayona, 2016), para algunos orígenes incluso bajos, aunque con una evidente dificultad de entrada en los barrios con mayor poder adquisitivo (Bayona y López-Gay, 2011).

El impacto de la concentración territorial, tanto de un grupo específico como de la pobreza o vulnerabilidad asociadas a áreas determinadas, sobre los residentes en estos espacios es lo que en la literatura científica se conoce como efecto barrio o neighbourhood effects (van Ham et al., 2012), y que se resume en la posibilidad de que la composición social y económica del entorno en que uno viva tenga un efecto negativo sobre sus residentes, ya sea sobre un plano económico, educativo o familiar. En el caso de los inmigrantes, la existencia del efecto barrio significaría, además, la estigmatización de sus lugares de residencia (y con ello, de las personas identificadas por el barrio donde viven) o de las escuelas donde sean mayoría, que conlleva asociada la aparición de menores oportunidades tanto en el campo educativo como en el laboral, lo que a la larga dificultaría su proceso de integración. El geógrafo Tom Slater (2015) niega que la estigmatización sea, en sentido estricto, un efecto barrio, aunque reivindica su peso en el crecimiento de las desigualdades.

En cuanto a la escuela, buena parte de los trabajos publicados recientemente sobre la distribución de los alumnos extranjeros o inmigrantes en los centros educativos de España se realiza desde la perspectiva de la segregación, con abundante bibliografía en Cataluña (Benito y González, 2007; Carrasco et al. 2007; Alegre et al. 2008; Sánchez-Hugalde, 2009; Bonal, 2012; Tarabini et al. 2018), donde existe además un especial interés sobre este tema por parte de las instituciones (Síndic de Greuges, 2008 y 2016), como lo demuestran los informes al respecto elaborados desde el Síndic de Greuges $^{1}$. Esta segregación escolar es, en Cataluña, mayor que en su contraparte residencial (López-Falcón y Bayona, 2012; Alegre, 2017),

1 El Síndic de Greuges es el Defensor del Pueblo en la Comunidad Autónoma de Cataluña. 
alcanzando unas intensidades que para Murillo y Martínez-Garrido (2018), con datos del último informe PISA, situarían la segregación escolar observada en España entre las más elevadas a escala europea. La explicación de los niveles de segregación en España es compleja, y según Bonal y Zancajo responde a una multiplicidad de causas, entre las que destacan cuestiones históricas, demográficas, institucionales y políticas (Bonal y Zancajo, 2018).

\subsection{Concepto y medida del fracaso escolar}

Internacionalmente el concepto de fracaso escolar descansa sobre el porcentaje de alumnos que no alcanzan a obtener los mínimos niveles exigidos en la educación obligatoria (Departament d'Ensenyament, 2013.) Para España, y a partir del año 1997, la educación obligatoria se fija en los 16 años, y corresponde al último de los cuatro cursos de la Educación Secundaria Obligatoria (ESO). El título de ESO es el que permite el acceso a la educación post-obligatoria (a excepción de algunos ciclos formativos) y el requerimiento mínimo de entrada a muchas de las ofertas laborables públicas. Se trata de una concepción convencional y restringida del "fracaso escolar" ${ }^{2}$, que en nuestro caso, y aún siendo conscientes de que no es la mejor medida sobre el rendimiento escolar, es la variable utilizada ${ }^{3}$.

La propia medición del rendimiento escolar es ya por si misma controvertida. Si bien la mejor manera de analizar el rendimiento es a partir del análisis de la adquisición de determinadas competencias, esto no es siempre posible. Siguen esta dirección los estudios realizados a partir del informe PISA, donde se examinan las competencias básicas adquiridas por los alumnos de 15 años de edad, pudiéndose diferenciar los resultados entre autóctonos e inmigrantes de primera y segunda generación. También el éxito o fracaso escolar puede ser medido a través de otras aproximaciones, ya sea estudiando las competencias adquiridas en otros cursos (sexto de primaria, por ejemplo), el porcentaje de repetidores a cualquier curso, o el porcentaje de menores con 11 y 15 años que cursan sexto de prima-

2 Ver Rujas, 2015, sobre la definición de fracaso escolar.

3 La no obtención del graduado en el año en curso no significa que el alumno no lo pueda obtener con posterioridad. 
ria y cuarto de ESO respectivamente (es decir, el curso que tocaría según su edad), lo que se conoce como tasa de idoneidad (Bolívar y López-Calvo, 2009).

Otro de los aspectos importantes en el fracaso escolar es la titularidad de la escuela. Bajo esta perspectiva, el rendimiento académico suele ser superior en la escuela privada que en la pública, produciéndose una huida de los hogares de clases medias hacia los centros de titularidad privada (Choi y Calero, 2012). En el caso de Cataluña, a pesar de los avances realizados durante los últimos años, los hijos de familias de clases altas o medias siguen teniendo más posibilidades de éxito escolar, diferenciación que la crisis económica habría incluso acentuado (Subirats, 2015). De hecho, entre las variables que determinan el éxito o fracaso escolar se encuentra habitualmente el nivel económico familiar (Bonal, 2015; González-Ferrer y Cebolla-Boado, 2018), situación que en el caso de los alumnos inmigrantes tiene un gran impacto sobre sus resultados.

\subsection{Concentración del alumnado inmigrante y fracaso escolar}

Para la mayoría de investigaciones, concentración de alumnos de origen inmigrante y fracaso escolar se encontrarían estrechamente relacionados. Garrido y Cebolla-Boado (2010) justifican esta interrelación a partir de cuatro grandes grupos de causas. En primer lugar, por la composición socioeconómica de las familias de los centros educativos con mayores concentraciones de población inmigrante, que sería inferior a la media, escolarizando como apuntan González-Ferrer y Cebolla-Boado (2018) a más alumnos de familias desaventajadas. En segundo lugar, por lo que se conocería como efecto escuela, donde en algunos contextos la localización de la escuela en espacios de concentración o en zonas vulnerables significa la existencia de menores recursos económicos, materiales y humanos en comparación con otros centros, y que en el caso de España puede añadirse las diferencias aportadas por la titularidad (pública o privada) de la misma. En tercer lugar, por los efectos del grupo o clase, especialmente si se sigue una política de distribución de los alumnos en diferentes grupos en función de sus características o resultados previos; y finalmente, en último lugar, por microinteracciones en centros con concentración de inmigrantes que 
significan un efecto contagio que provocará un impacto negativo sobre el rendimiento escolar. Según los mismos autores, una vez controladas las características sociales de los alumnos, estos efectos son débiles y en el caso de España únicamente se observan en escuelas con concentraciones por encima del 20\% (Cebolla-Boado y Garrido, 2011, empleando datos del informe PISA del año 2006) de alumnos inmigrantes. Años más tarde, Calero y Escardíbul (2016) identifican el mismo efecto concentración sobre los resultados escolares, y que afectarían tanto a inmigrantes como a los alumnos autóctonos. Con datos de 2012, los efectos observados se producirían a partir de niveles significativos de concentración, en este caso ligeramente superiores a los anteriores, y del 30\% para los autóctonos y del 40\% entre los alumnos inmigrantes. En cuanto a la segregación escolar, para Murillo y Martínez-Garrido (Murillo y Martínez-Garrido, 2018), y con datos del último informe PISA de 2016, en España se situaría entre las más elevadas a escala europea. La selección inicial de la escuela por parte de los padres es según el informe del Síndic de Greuges (2016), una de las principales causas de la segregación escolar en Catalunya. La progresiva diversificación de los proyectos educativos de las escuelas facilita que las familias autóctonas, más conocedoras de las características y diferencias entre centros, ejerzan una selección de los mismos, produciéndose además una salida desde las escuelas con mayores concentraciones. El impacto de la crisis económica ayuda a magnificar estas diferencias (Síndic de Greuges, 2016). Además, se estaría produciendo un fenómeno de "white flight" (Sánchez-Hugalde, 2009), con un traspaso de alumnos hacia la escuela privada o hacia otras escuelas públicas con menor presencia de extranjeros.

En general, la mayoría de los trabajos académicos no llegan a identificar una relación clara entre concentración y resultados escolares. Depende, por un lado, de qué aspecto de los resultados se esté midiendo, de cómo se mida la concentración, y del país considerado. De esta forma, encontramos casos como el de Schneeweis (2015), que en Austria y analizando la repetición de grado, encuentra que el porcentaje de alumnos inmigrantes no tiene efecto alguno para la población autóctona, pero si sobre los alumnos inmigrados, aumentando la repetición, y con unos efectos negativos especialmente intensos si la concentración es de alumnos del mismo origen. En otros casos no se observa relación alguna entre concentración y rendimiento (Hardoy y Mastekaasa, 2018, 
para Noruega). Para Cataluña, y después de controlar por diversas variables asociadas al proceso migratorio, la concentración tiene una relación con el fracaso escolar, aunque esta relación es débil y sólo significativa para los alumnos autóctonos (Bayona et al, en prensa).

\section{DATOS ESTADÍSTICOS Y METODOLOGÍA}

Para la realización de este trabajo se han utilizado los microdatos de los alumnos matriculados en enseñanzas no universitarias en Cataluña durante el curso 2015-2016. Estos datos han sido cedidos por el Departament d'Ensenyament de la Generalitat de Cataluña, y mediante un convenio con el Institut d'Estadística de Catalunya (Idescat), se han enlazado con el Registro Estadístico de la Población - estadística que relaciona las tradicionales fuentes estadísticas, como el Padrón Continuo de Población, con las estadísticas basadas en registros administrativos-, lo que nos ha permitido recuperar la información sociodemográfica de los alumnos y de sus familias que consta en el Padrón, como su año de entrada en Cataluña, y el origen de sus progenitores. Con esta información se ha construido una tipología que ha distribuido a los alumnos en varias categorías, definidas a partir del lugar de nacimiento del alumno y del de sus progenitores, así como del año de llegada del alumno ${ }^{4}$, siguiendo los trabajos sobre integración escolar de los descendientes de inmigrantes realizados por Rumbaut (2004). En este artículo a esta tipología se le denomina como "estatus migratorio" del alumno, y contiene cinco grandes grupos. Si los alumnos han nacido en España y también lo han hecho sus progenitores, se identifica al alumno como "autóctono". En el caso de haber nacido en España y uno de sus progenitores también, mientras el otro ha nacido fuera del país, hablaremos de "generación 2,5"; si quienes han nacido fuera son ambos progenitores los etiquetamos como alumnos de "segunda generación" (también en el caso de constar un único progenitor, y este hubiera nacido en el exterior). Cuando es el alumno el que ha nacido fuera de España, si ha llegado con siete o más años a

4 El año de llegada se infiere de la alta en el sistema padronal en Cataluña, desconociendo si anteriormente el alumno había estado empadronado en otro municipio español. 
Cataluña los agrupamos como "primera generación", mientras que si ha llegado con una edad inferior hablaremos de "generación 1,75". Esta diferenciación se realiza a partir de la edad en que todos los alumnos deberían estar cursando el primer curso de primaria, y por tanto, se incorporarían desde un primer momento al sistema escolar obligatorio. Al no disponer directamente de la edad, se ha utilizado el año de nacimiento del alumno, en este caso los alumnos nacidos en 2009, para diferenciar ambas categorías.

Aplicando esta tipología se recupera la información del 97,3\% del alumnado. A pesar de la amplia cobertura alcanzada, una pequeña parte de los mismos no han podido ser reasignados por falta de datos. Debido a ello (y a la sobrerrepresentación de las situaciones más complejas entre los datos extraviados) se ha conservado para el análisis a un grupo de alumnos nacidos fuera de España pero de los que se desconoce el año de llegada, que se han clasificado como "otros inmigrados" y que no alcanzan al 1\% del alumnado. Nótese que la tipología se construye sin atender a la nacionalidad, con lo cual alumnos con nacionalidad extranjera pueden ser clasificados como autóctonos si ellos y sus progenitores han nacido en España.

En segundo lugar, y con la intención de abarcar una mayor diversidad de situaciones, se ha realizado un análisis por origen basado en la tipología generacional. De esta forma, y bajo un mismo epígrafe, se consideran todos los alumnos relacionados con el proceso migratorio de un mismo origen nacional, ya sean primeras generaciones, como generaciones 2,5 y conserven o no la nacionalidad. Para ello, se han escogido y reconstruido 12 de los principales orígenes presentes en la escuela en Cataluña en base a cinco criterios: 1) el volumen de los grupos, escogiendo algunos de los más significativos; 2) el porcentaje de fracaso escolar experimentado; 3) las trayectorias migratorias, identificadas a partir de la bibliografía, con orígenes con perfiles muy masculinizados que además reagrupan a chicos, mientras en otros casos los perfiles son feminizados; 4) la relación con el estatus migratorio, intentando que los grupos más representativos de cada uno de ellos estén presentes en la selección; y 5) las diferencias de género en los resultados escolares. Bajo estos criterios de selección, se han estudiado los doce orígenes siguientes: Marruecos, Rumania, China, Bolivia, Paquistán, Ecuador, Argentina, Honduras, Senegal, Gambia, República Dominicana y la India. En esta operación, y para favorecer la exhaustividad, se ha utilizado también la variable nacionalidad para recuperar los casos de alum- 
nos donde faltaba algún dato estadístico, especialmente cuando no conocemos el país de nacimiento. Este proceso de asignación puede producir el caso particular de alguna doble adscripción, cuando los progenitores pertenecen a orígenes distintos, por lo que se ha descartado utilizar los totales de este ejercicio.

La información sobre la obtención del graduado de ESO sólo se encuentra disponible para las escuelas públicas ${ }^{5}$, las cuales concentran una parte importante de la población inmigrada o descendiente de inmigrantes. Según ciclo educativo, el número de escuelas y su titularidad difiere, con mayor diversidad en las primeras etapas educativas. De esta forma, en el segundo ciclo de infantil existen 2.308 escuelas, 1.700 públicas y 608 de privadas. En la educación primaria el número de escuelas es similar (2.313), con 1.711, el 74\%, de titularidad pública, mientras que se observa una substancial reducción del número de centros en la educación secundaria, con 1.083 centros, y donde la escuela pública representa únicamente el $52 \%$ de ellos. Las escuelas públicas se caracterizan por concentrar al alumnado relacionado con la inmigración. En ellas, por ejemplo, estudia el $62,5 \%$ del total del alumnado de secundaria. Este porcentaje, según el estatus migratorio, desciende al 59,3\% para los autóctonos, e incluso con valores por debajo se sitúan los escolares de la generación 2,5 con un 57,2\%. En cambio, el 79,5\% del alumnado de primera generación se encuentra en la pública, o el 75,1\% de la segunda generación y el 73,6\% de la generación 1,75. Estas diferencias en la distribución también son observadas entre escuelas del mismo sistema (Síndic de Greuges, 2016), y son mayores en algunos ámbitos urbanos.

En cuanto a la concentración, ésta se define a partir del porcentaje que representan todos los alumnos relacionados con el fenómeno migratorio sobre los alumnos totales, siendo la unidad de análisis la escuela. En el caso particular del análisis de la relación entre fracaso escolar y concentración, sólo se considera para este cálculo a los escolares de cuarto curso de ESO, y no los del conjunto del centro educativo.

En un primer momento se analiza también el grado de segregación escolar, recurriendo a la utilización de uno de los indicadores más

5 En Cataluña debe tenerse en cuenta que históricamente el peso de las escuelas privadas (concertadas en su mayoría) es importante, especialmente en la ciudad de Barcelona. 
$\operatorname{conocidos}^{6}$ : el índice de segregación (IS). Este indicador compara la distribución de un grupo de población en relación al total, con valores que se sitúan entre 0 y 1 . Valores próximos a 0 muestran cómo dos grupos se distribuyen exactamente de la misma forma, mientras que el valor de 1 indicaría que no existe coincidencia alguna. Los valores se encuentran, por lo tanto, condicionados por la distribución territorial del grupo en Cataluña. La formulación de este indicador es la siguiente:

$$
I S=\frac{1}{2} \sum_{i=1}^{n}\left|\frac{x_{i}}{X}-\frac{t_{i}-X_{i}}{T-X}\right|
$$

En esta ecuación $\mathrm{x}_{i}$ son los alumnos de un grupo determinado en una escuela i; X el total de alumnos de la categoría en Cataluña; $t_{i}$, el total de alumnos en la escuela $\mathrm{i}$; $\mathrm{T}$ es el total de alumnos de Cataluña, y n es el número de escuelas. Este indicador es una versión del Índice de Disimilitud (Massey y Denton, 1988), que a diferencia del Índice de Segregación indica la distancia en la distribución de dos subgrupos.

\section{INMIGRACIÓN Y ESCUELA EN CATALUÑA}

No es hasta finales de siglo XX e inicios del XXI cuando a raíz del boom migratorio internacional crece la diversidad por orígenes entre los alumnos de las escuelas catalanas. Los datos publicados por el Ministerio de Educación y el Departament d'Ensenyament hacen referencia al alumnado según su nacionalidad. Desde esta perspectiva, y según la primera fuente, apenas 15 mil alumnos extranjeros se encontraban matriculados en Cataluña a mediados de los noventa, y poco más de 24 mil en el curso 2000-2001. Es a partir de entonces que se observa un constante e intenso crecimiento, que

6 Somos conscientes que existe una amplia variedad de indicadores para medir esta diferenciación, aunque los resultados obtenidos normalmente difieren poco de los más habituales. Por ejemplo, recientemente Murillo, MartínezGarrido y Belavi (2017) en el mismo campo educativo han considerado el índice de Gorard, que también se deriva del índice de Disimilitud. La utilización de un mismo indicador, a pesar de posibles deficiencias, mejora la comparabilidad, ya por sí difícil. 
conforme el Departament d'Ensenyament se sitúa en 54 mil alumnos en 2002-2003, valores que se triplican en 2008-2009. A partir de este curso el crecimiento se reduce, estabilizándose más tarde y alcanzando un máximo de 168 mil alumnos en 2011-2012, con un leve descenso posterior hasta los 161 mil alumnos en 2016-2017. Claramente los datos por nacionalidad están mediatizados por las nacionalizaciones, crecientes en los últimos años ${ }^{7}$.

$\mathrm{Si}$, en cambio, clasificamos el alumnado empleando la tipología del estatus migratorio, las cifras resultantes se multiplican, hasta alcanzar en la actualidad los 317.373 alumnos (el 25,9\% de todos los alumnos), de los cuales 269.261 se encuentran cursando el segundo ciclo de infantil, educación primaria o secundaria (figura 1, izquierda). Los datos del curso 2015-2016 visibilizan una situación cambiante y de evolución desigual. Los porcentajes de alumnos relacionados con el proceso migratorio son muy similares, aunque aumentan en los últimos y los primeros cursos. Pero, lo que conoce cambios importantes entre cursos es el estatus migratorio, ya que en la educación secundaria son más importantes los alumnos nacidos en el extranjero, mientras cada vez más se abren paso las segundas generaciones. Como resultado la complejidad escolar aumenta ligeramente, aunque cambia la composición de la misma.

El análisis de la distribución geográfica de la población inmigrante en Cataluña es indispensable en relación a la concentración. Encontramos una presencia territorial dispar, especialmente si nos fijamos en los orígenes, y responde a una periodización de los flujos migratorios que difiere entre nacionalidades y que prioriza las áreas más pobladas. La concentración en la Región Metropolitana de Barcelona, o bien en los municipios litorales es notable, especialmente en la educación secundaria, donde el número de institutos es menor (figura 1, mapa). Únicamente 268 municipios catalanes cuentan con un instituto de secundaria. En ellos, 132 municipios muestran valores por debajo del $20 \%$ de alumnos de origen inmigrante, en cambio, hasta 44 de ellos superan el 30\%, con valores que en algunos municipios rebasan el 50\% (Guissona, Cadaqués y Salt). Entre las ciudades más pobladas, en L'Hospitalet de Llobregat el 46,3\% de los alumnos son de origen inmigrante, o el 36,8\% en Santa Coloma de Gramenet. En Barcelona este valor se sitúa en el $29 \%$.

7 Por ejemplo, entre los años 2007 y 2016 en Catalunya hasta 44.811 menores de 14 años de nacionalidad extranjera adquirieron la nacionalidad española. 
FIGURA 1

\section{PROPORCIÓN DE ALUMNOS SEGÚN EL ESTATUS MIGRATORIO Y EN SU DISTRIBUCIÓN TERRITORIAL (CUARTO DE ESO), CATALUÑA, 2015-2016}

Alumnos según estatus migratorio en Cataluña

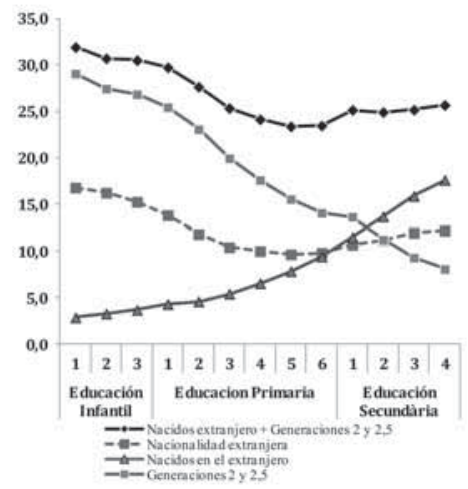

Peso sobre el total de alumnos (por localización de la escuela, $4^{\circ} \mathrm{ESO}$ )

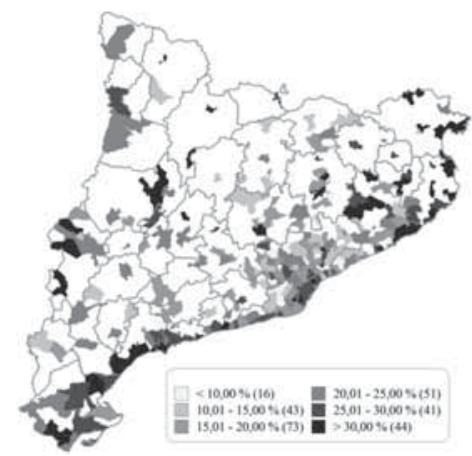

Fuente: Departament d'Ensenyament e Idescat.

En cuanto a los orígenes, la presencia de alumnado de origen marroquí es muy superior al resto de grupos (Cuadro 1), aunque existe un amplio conjunto de orígenes que superan el umbral de los mil alumnos, entre los que se encuentran ecuatorianos, rumanos, chinos o argentinos, ejemplo de la elevada diversidad. Entre los doce seleccionados, los países centroamericanos destacan entre el alumnado de primera generación, ya que son los orígenes con flujos migratorios más recientes, mientras que en la generación 1,75 son muy visibles los pakistaníes, donde la reagrupación familiar era muy intensa alrededor de una década atrás. Entre la segunda generación, además de la representatividad del alumnado marroquí, es importante visibilizar a los gambianos, uno de los colectivos con una presencia más prolongada en el país, que provoca que en cuarto curso de secundaria sean el segundo origen entre los alumnos de segunda generación. Es importante señalar como, a excepción de hondureños, la segunda generación es la tipología siempre más representada. Finalmente, la generación 2,5 es muy importante entre los argentinos, pero también entre los dominicanos. 
CuAdro 1

ALUMNOS CATALANES SEGÚN EL ESTATUS MIGRATORIO Y EL PAÍS DE “ORIGEN”, CURSO 2015-2016

\begin{tabular}{|c|c|c|c|c|c|c|c|}
\hline & $\begin{array}{c}\text { Primera } \\
\text { Generación }\end{array}$ & $\begin{array}{c}\text { Generación } \\
1,75 \\
\end{array}$ & $\begin{array}{c}\text { Segunda } \\
\text { Generación }\end{array}$ & $\begin{array}{c}\text { Generación } \\
2,5 \\
\end{array}$ & $\begin{array}{c}\text { Otros } \\
\text { inmigrantes }\end{array}$ & $\begin{array}{l}\text { otros } \\
\text { casos }\end{array}$ & Total \\
\hline Marruecos & 2.800 & 7.824 & 53.390 & 3.292 & 2.233 & 875 & 70.414 \\
\hline Ecuador & 1.554 & 2.421 & 10.633 & 2.461 & 237 & 199 & 17.505 \\
\hline Rumania & 1.385 & 3.312 & 6.456 & 1.581 & 839 & 502 & 14.075 \\
\hline China & 1.287 & 3.803 & 7.002 & 233 & 941 & 245 & 13.511 \\
\hline Argentina & 526 & 2.133 & 4.486 & 4.324 & 228 & 20 & 11.717 \\
\hline Bolivia & 1.696 & 2.312 & 4.490 & 696 & 206 & 187 & 9.587 \\
\hline Rep. Dominicana & 1.588 & 967 & 4.050 & 1.605 & 243 & 131 & 8.584 \\
\hline Paquistán & 1.533 & 2.325 & 2.725 & 113 & 476 & 86 & 7.258 \\
\hline Honduras & 1.794 & 897 & 1.343 & 400 & 364 & 201 & 4.999 \\
\hline Gambia & 262 & 321 & 3.396 & 103 & 120 & 74 & 4.276 \\
\hline Senegal & 389 & 625 & 2.327 & 224 & 140 & 46 & 3.751 \\
\hline India & 524 & 982 & 1.657 & 120 & 187 & 28 & 3.498 \\
\hline Total (12) & 15.338 & 27.922 & 101.955 & 15.152 & 6.214 & 2.594 & 169.175 \\
\hline
\end{tabular}

Fuente: Departament d'Ensenyament e Idescat.

\section{RESULTADOS. CONCENTRACIÓN Y SEGREGACIÓN SEGÚN ESTATUS MIGRATORIO}

\subsection{La segregación y su relación con el fracaso escolar}

El fracaso escolar sólo puede ser analizado, con los datos disponibles, para el alumnado que se encuentra en el cuarto curso de ESO y en institutos públicos en Cataluña, contando con información estadística de 538 centros. Como introducción, se ha relacionado los valores de segregación escolar calculados con el índice de Segregación (IS) y el porcentaje de fracaso escolar para los distintos estatus y para los doce orígenes nacionales (figura 2). Los resultados muestran la existencia de una clara correlación entre segregación y proporción de alumnos con fracaso escolar. A mayor segregación (en comparación con el conjunto de escolares) mayores niveles de fracaso. Según el estatus migratorio, son los escolares de la primera generación los que muestran unas pautas de distribución escolar más alejadas del conjunto, los mismos alumnos que experimentan un fracaso superior. Esta segregación más elevada indica como los alumnos incorporados en los últimos años debido a nuevas inmigraciones lo hacen 
en pocas escuelas y de forma muy localizada geográficamente, en especial aquellos alumnos inmigrados que se escolarizan en edades próximas a la entrada al mercado laboral. Existe una serie de escuelas "especializadas" en la recepción de los alumnos de incorporación reciente. En estas edades aumenta, y mucho, el fracaso, particularmente si existe un desconocimiento de las lenguas vehiculares del país. En contraposición, los valores de segregación para la generación 1,75 son relativamente bajos, menores que el resto de grupos, visibilizando la diversidad de orígenes de la migración internacional recibida antes de la crisis económica y su amplia dispersión territorial. Su segregación es menor que la de la generación 2,5 y, en contra de lo esperado, incluso que la de los mismos autóctonos, situación que debe explicarse por las posibles pautas de evitación de escuelas con altos porcentajes de inmigrantes por parte de estos últimos. Para los escolares de la segunda generación, los niveles más altos de segregación se explicarían también por este último hecho, aunque al mismo tiempo debemos considerar un efecto de composición por origen, ya que entre la segunda generación, cursando cuarto de ESO y en escuelas públicas, los hijos de marroquíes representan más del $45 \%$ de los casos, a los que se suman un considerable número de gambianos (el 8\%), en ambas situaciones colectivos con valores de segregación residencial generalmente por encima de la media en Cataluña (Achebak et al. 2017; Galeano et al. 2015).

En cuanto a los orígenes, la relación observada es incluso más sustancial, y a mayor segregación sigue observándose un fracaso superior. Algunos de los grupos más segregados lo son, en Cataluña, por una implantación territorial restringida a pocas comarcas. Es lo que ocurre con los gambianos o senegaleses, más presentes en zonas del este del país, o con los pakistaníes, con alta representatividad en Barcelona. En cambio, argentinos y marroquíes muestran los valores menores, los primeros por presentar pautas muy similares a los autóctonos en su distribución residencial, los segundos por ser el colectivo con mayor dispersión geográfica. En general, se observa como los grupos que territorialmente se asemejan más al conjunto de alumnos son los que menores diferencias encuentran en el fracaso escolar. En cambio, altos valores de fracaso se visibilizan en grupos donde buena parte de los alumnos acaban de llegar (por ejemplo, los hondureños, donde la mayoría de alumnos son de la primera generación), o situaciones particulares como el de los gambianos, donde a pesar de que los alumnos son generalmente nacidos en Cataluña, el fracaso escolar es excepcional. 
FIgURA 2

\section{RELACIÓN ENTRE LA SEGREGACIÓN Y EL FRACASO ESCOLAR, POR ORÍGENES, CURSO 2015-2016}
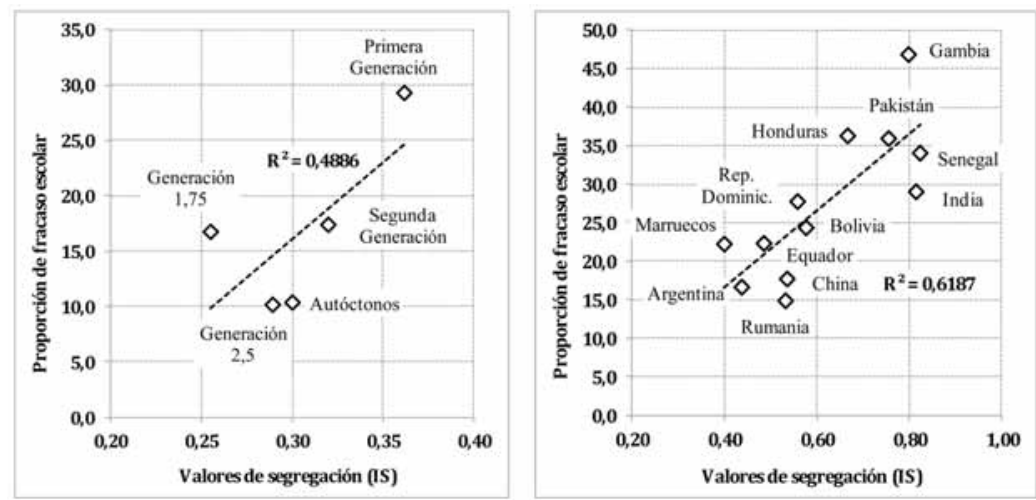

Fuente: datos del Departament d'Ensenyament e Idescat.

\subsection{La concentración en las escuelas}

La concentración escolar del alumnado inmigrado o de origen inmigrado puede ser uno de los elementos que justifiquen los resultados escolares obtenidos. Para determinar esta posible relación en primer lugar se presentan los datos globales de la distribución de los alumnos en función de su estatus migratorio y de la nacionalidad y origen (figuras 3 y 4), diferenciando por titularidad (pública/privada) y para las principales etapas educativas. Para esta representación, la concentración se define por el peso de cada grupo analizado sobre el total de alumnos de su mismo ciclo y escuela.

En la figura 3 se puede ver claramente como en las dos categorías donde el menor ha nacido en España (segunda generación y generación 2,5) la concentración es actualmente mayor en las primeras etapas educativas, mientras que en la educación secundaria esta situación es menos frecuente. De hecho, los alumnos nacidos en España de progenitores nacidos en el extranjero constituyen una situación reciente, y por lo tanto aún poco visible en las etapas educativas más avanzadas. La concentración de las segundas generaciones es más visible, ya que el grupo se encuentra más representado. A diferencia de otros estatus, en la generación 2,5 las diferencias 
FiguRA 3

DISTRIBUCIÓN DE LAS ESCUELAS SEGÚN ETAPA EDUCATIVA, TITULARIDAD Y PROPORCIÓN DE ALUMNOS SEGÚN EL ESTATUS MIGRATORIO, CURSO 2015-2016
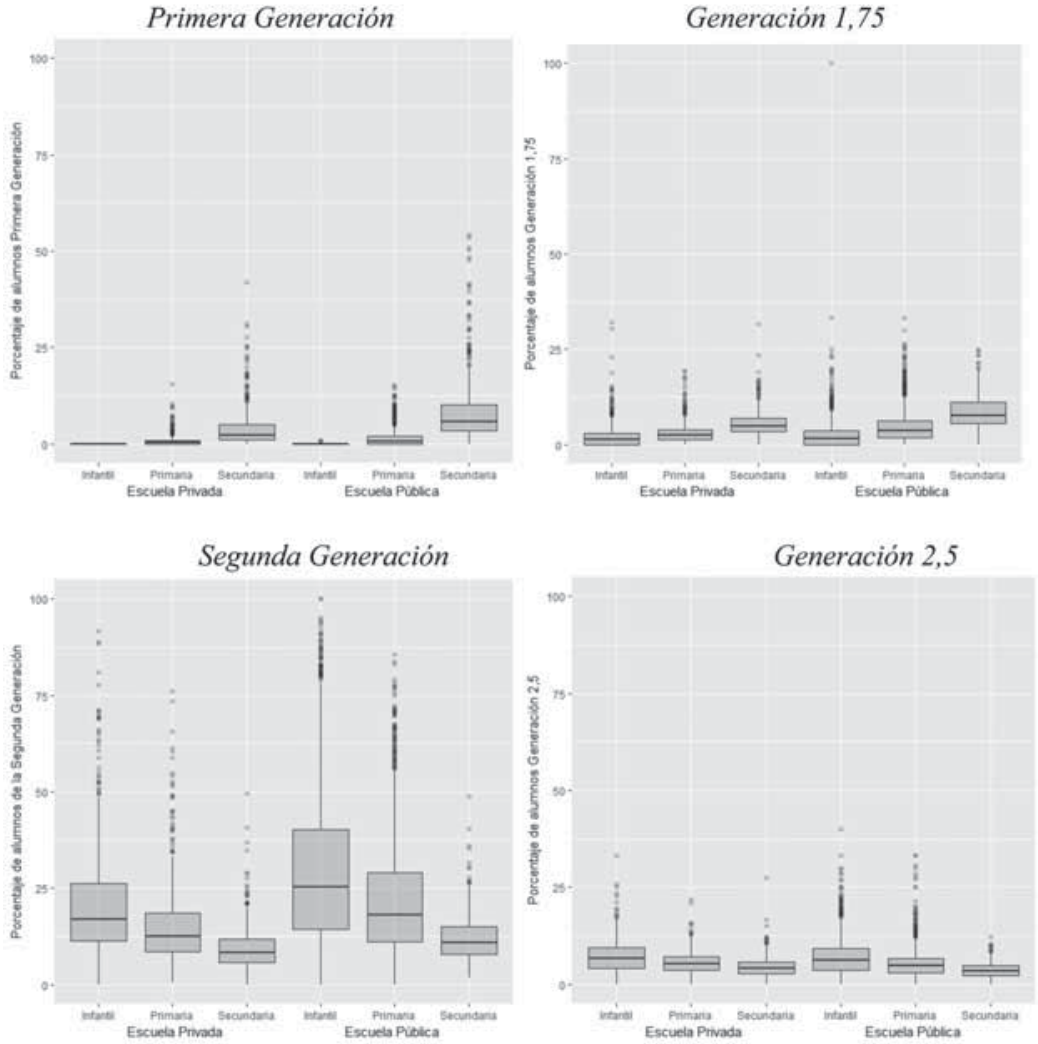

Fuente: datos del Departament d'Ensenyament e Idescat.

por titularidad de la escuela se diluyen. En la educación infantil, la segunda generación tan solo se encontraría ausente en 188 escuelas (en su mayoría pequeñas, donde estudian 4.797 alumnos). La concentración media de alumnos de la segunda generación es del 20,5\%, y en 211 escuelas se supera el umbral del 50\% (de ellas, 19 
Figura 4

\section{DISTRIBUCIÓN DE LAS ESCUELAS SEGÚN LA ETAPA EDUCATIVA, LA TITULARIDAD Y LA PROPORCIÓN DE ALUMNOS EXTRANJEROS E INMIGRADOS, CURSO 2015-2016}
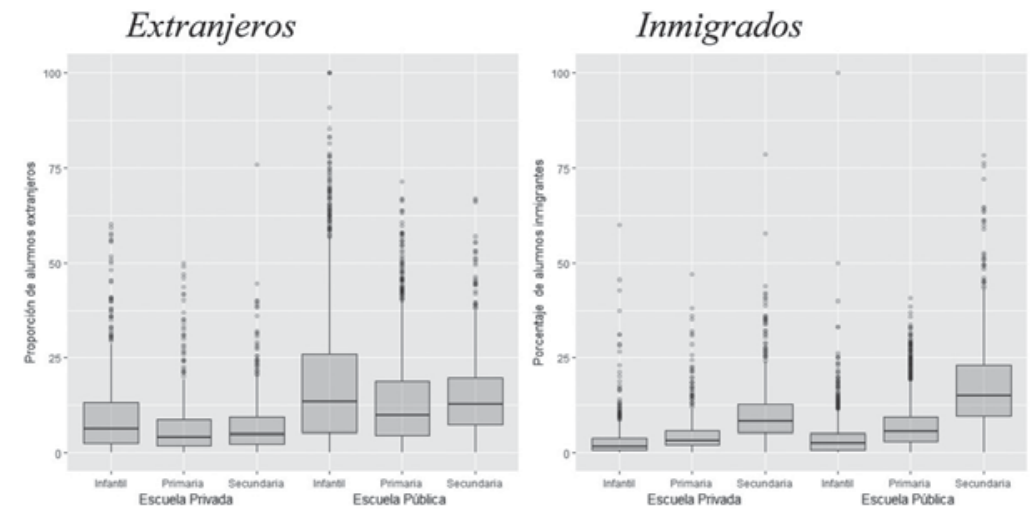

Fuente: datos del Departament d'Ensenyament e Idescat.

son privadas). Incluso en 47 escuelas los porcentajes sobrepasan el $75 \%$ o más, con una amplia distribución territorial (Salt, Manresa, Lleida, Girona y Barcelona). Por su parte, la generación 2,5 no la encontramos en 235 escuelas, y supera el $20 \%$ en tan solo 34 centros, la mayoría de ellos con un número reducido de alumnos. En cambio, entre los dos grupos de alumnos nacidos en el extranjero (generación 1 y 1,75), la concentración crece en los cursos superiores. Si entre la primera generación esto se explica en parte por la propia definición del grupo (llegados con siete o más años), en la generación 1,75 el aumento relativo entre etapas denota un proceso migratorio más intenso en el pasado. Entre los primeros, la concentración más elevada se observa nuevamente en la escuela pública, alcanzando en casos particulares valores más que notables. Es la situación de una escuela de L'Hospitalet de Llobregat, donde el 50,2\% de los alumnos ha llegado de forma reciente.

Si se contempla la nacionalidad (extranjeros), en la educación infantil se advierte una notable dispersión debido al elevado número 
de escuelas, aunque en la escuela pública el 19,7\% de los alumnos son extranjeros, por solo el 8,4\% de la privada (ver figura 4). En la educación primaria descienden estos valores $(13,5 \%$ y $5,6 \%$ respectivamente), descenso en parte por las nacionalizaciones, mientras que en secundaria disminuye la dispersión (se trata de menos escuelas) y aumenta la presencia media de extranjeros $(14,7 \%$ y $6,1 \%)$. El máximo valor supera el $75 \%$ (en una escuela privada de alto standing), mientras que en sólo 18 escuelas no hay presencia de alumnos extranjeros. Desde la perspectiva del lugar de nacimiento (inmigrados) la concentración de alumnos inmigrantes es muy diferente. Los valores crecen desde el 3,3\% de infantil, al 6,3\% de primaria y el $14,6 \%$ de secundaria. Las cifras en la pública son superiores $(3,6 \%$ y $7,3 \%$ en las dos primeras etapas, con un fuerte aumento al $17,7 \%$ en secundaria). En cambio, los valores de la privada resultan siempre inferiores $(2,7 \%, 4,2 \%$ y $9,3 \%$ respectivamente). El crecimiento en la última etapa educativa es el efecto indirecto de la evolución diferencial de los flujos migratorios a Cataluña.

\subsection{Concentración y fracaso escolar}

Como se ha apuntado anteriormente, la información sobre la obtención del grado de ESO se encuentra disponible sólo para el alumnado de escuelas públicas. En total se trata de 42.797 alumnos, aunque en un 3,2\% de los casos esta información no se conoce, con lo que el fracaso escolar es estudiado en relación a 41.442 alumnos ${ }^{8}$.

La representación de los porcentajes de fracaso en relación con los valores de concentración (agrupados en intervalos de diez puntos porcentuales) muestra la existencia de una correlación positiva entre los niveles de concentración de alumnos inmigrantes o extranjeros en la escuela y el fracaso (o éxito) escolar de los alumnos ${ }^{9}$. Esta correlación es positiva: a mayor concentración mayor fracaso escolar, y este se produce con intensidades similares ya sea

8 Se ignora cuantos alumnos han abandonado previamente la escuela al alcanzar los 16 años de edad, con lo cual las cifras de fracaso pueden estar subrepresentadas para algunos colectivos.

9 Los valores de concentración se calculan en función de la variable de referencia (nacionalidad, nacidos en el extranjero o la suma de situaciones vinculadas a la migración), es por ello que los totales difieren. 
considerando la nacionalidad, empleando el lugar de nacimiento del alumno o la tipología del estatus migratorio (figura 5). Incluso estos valores son ligeramente superiores si se analiza a los alumnos según la nacionalidad en comparación a los datos por origen. Esto que es cierto para el conjunto del alumnado, y que al fin y al cabo traduce un efecto composición, esconde una mayor complejidad.

\section{FIGURA 5}

RELACIÓN ENTRE CONCENTRACIÓN (EJE ABSCISAS) Y PORCENTAJE DE FRACASO ESCOLAR (EJE ORDENADAS), POR NACIONALIDAD, LUGAR DE NACIMIENTO Y ESTATUS, CURSO 2015-2016
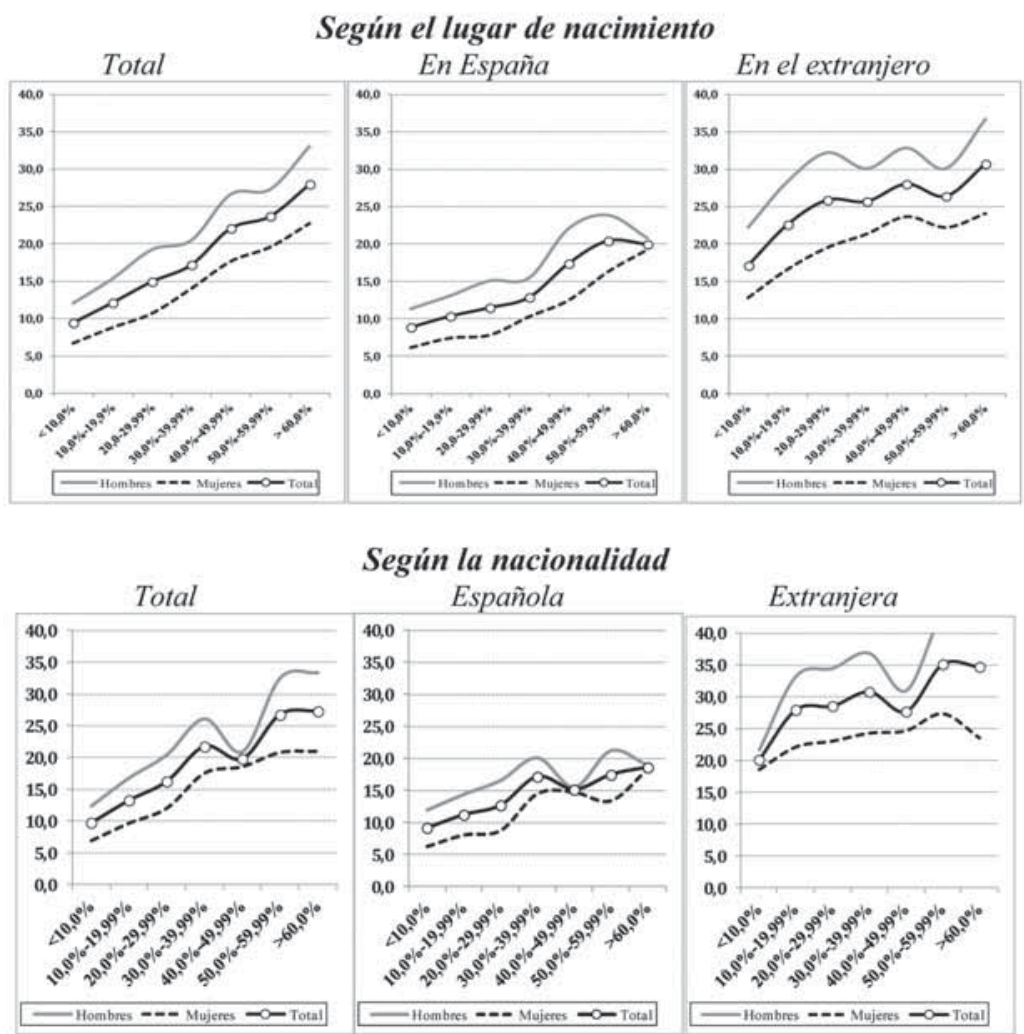

Según la nacionalidad
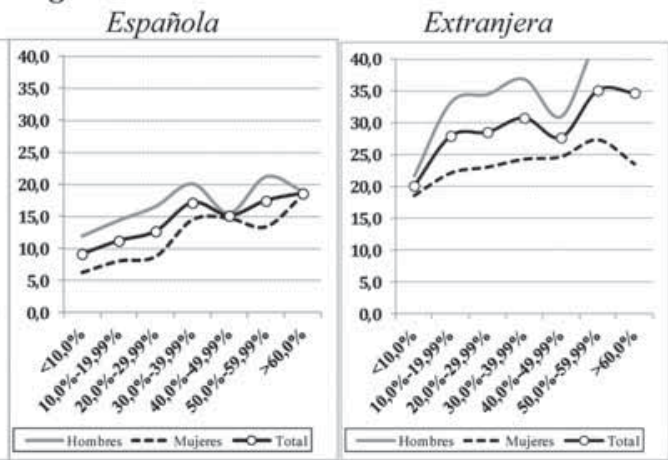
Figura 5 (continuación)

RELACIÓN ENTRE CONCENTRACIÓN (EJE ABSCISAS) Y PORCENTAJE DE FRACASO ESCOLAR (EJE ORDENADAS), POR NACIONALIDAD, LUGAR DE NACIMIENTO Y ESTATUS, CURSO 2015-2016

\section{Según estatus migratorio}

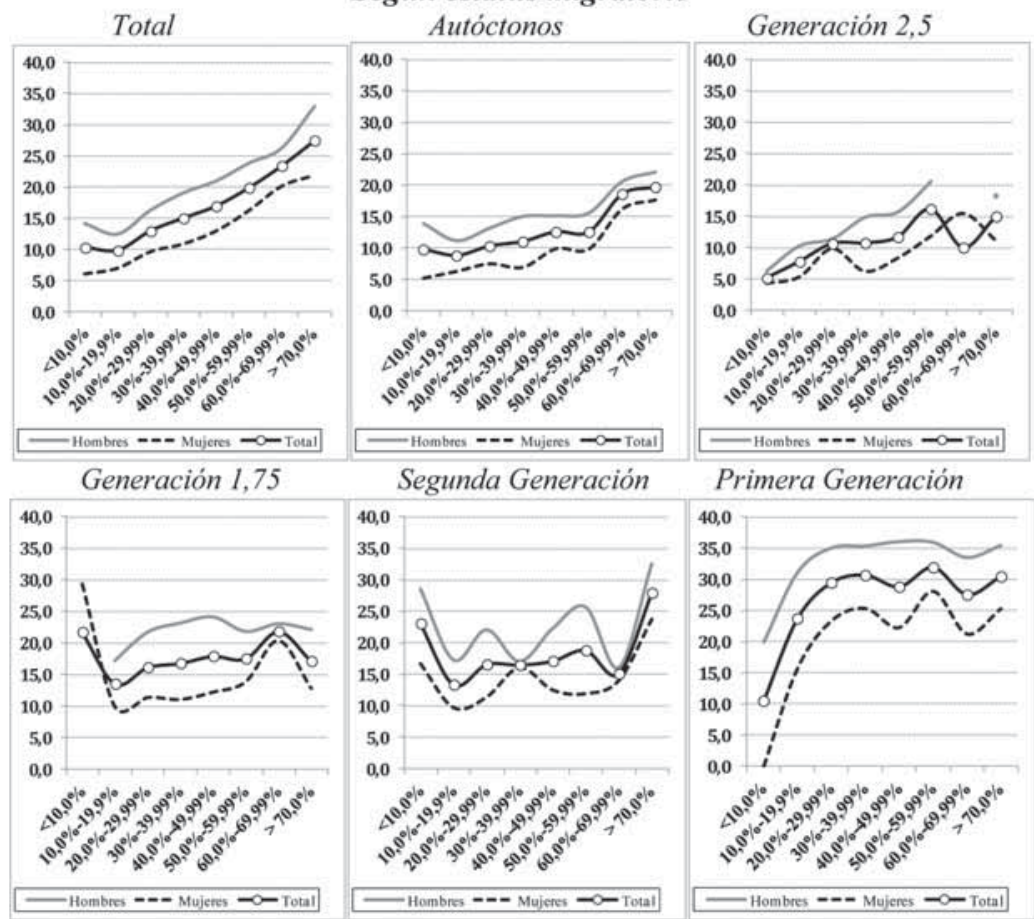

Fuente: datos del Departament d'Ensenyament e Idescat.

Desde el punto de vista del lugar de nacimiento, y comparando a los escolares nacidos en el extranjero con los nacidos en España, se constata como el efecto concentración resulta más intenso entre los nacidos en España que entre los nacidos fuera. En este segundo caso, tan sólo puede indicarse cómo por debajo de un 20\% de concentración existe una mejora de los resultados, mientras que por encima no se produce aumento significativo del fracaso hasta traspasar el umbral del 60\%. Desde la perspectiva de la nacionalidad, 
y comparando alumnos españoles con extranjeros, se alcanzan resultados similares. Para los españoles la relación es continua, prácticamente duplicando la incidencia del fracaso, en cambio, para los extranjeros, en valores de concentración entre el $10 \%$ y el $50 \%$ el fracaso se mantiene estable en torno al 30\%, y tan sólo aumenta al superar el $50 \%$ de los alumnos. De forma similar a lo observado anteriormente, los bajos niveles de concentración sí que significan menores niveles de fracaso, como ocurre con los alumnos que estudian en clases con menos del 10\% de alumnos extranjeros.

En tercer lugar, y considerando la concentración como la suma de las diferentes categorías relacionadas con la inmigración, aparecen resultados ligeramente divergentes. En esta ocasión, para los autóctonos se constata un efecto negativo de la concentración, aunque es de baja intensidad y únicamente se aleja de la media por encima de concentraciones del $60 \%$, cuando el fracaso rebasa umbrales del $18 \%$. Para la generación 2,5 los casos disponibles son escasos, y únicamente puede comentarse los mejores resultados obtenidos cuando la concentración es prácticamente inexistente. En las tres situaciones restantes se puede contemplar un ligero aumento del fracaso relacionado con la concentración, aunque este es poco importante y solo se visibiliza de forma clara en los extremos de la distribución. En los tres casos analizados los efectos de la concentración son complejos, y parecen afectar principalmente a los autóctonos (o con nacionalidad española o nacidos en España, respectivamente). Este efecto acostumbra a ser cuantitativamente reducido, y puede esconder diferencias socioeconómicas de los alumnos, en especial cuando en las escuelas con mayores proporciones de alumnos inmigrantes se dan procesos de white flight. En todos los casos, esta situación indica como son los autóctonos los que tienen mayores dificultades cuando el porcentaje de extranjeros o inmigrantes es elevado.

Estos resultados, en un contexto de fuerte diversidad entre centros públicos y una doble línea escolar pública-privada, pueden corresponderse con la imposibilidad de las familias de clases sociales más bajas de reubicar a sus hijos en otras escuelas. A pesar de ello, debemos puntualizar que los resultados presentados se refieren al conjunto de Cataluña, y que estas dinámicas a escala de ciudad o municipio podrían ser incluso más notables o comportarse de forma desigual. 


\subsection{Origen, concentración y fracaso escolar}

Finalmente, y desde la perspectiva de los 12 orígenes, abordamos también la relación entre fracaso y concentración. A diferencia de los análisis anteriores, en cada uno de los orígenes confluyen una alta gama de situaciones migratorias que se han obviado por su baja representatividad. En este caso, nos interesa observar a estos colectivos definidos de una forma más amplia que en las visiones

Figura 6

\section{PROPORCIÓN DE ALUMNOS POR ORIGEN Y GRADO DE CONCENTRACIÓN, CUARTO DE ESO, ESCUELAS PÚBLICAS, 2015-2016}

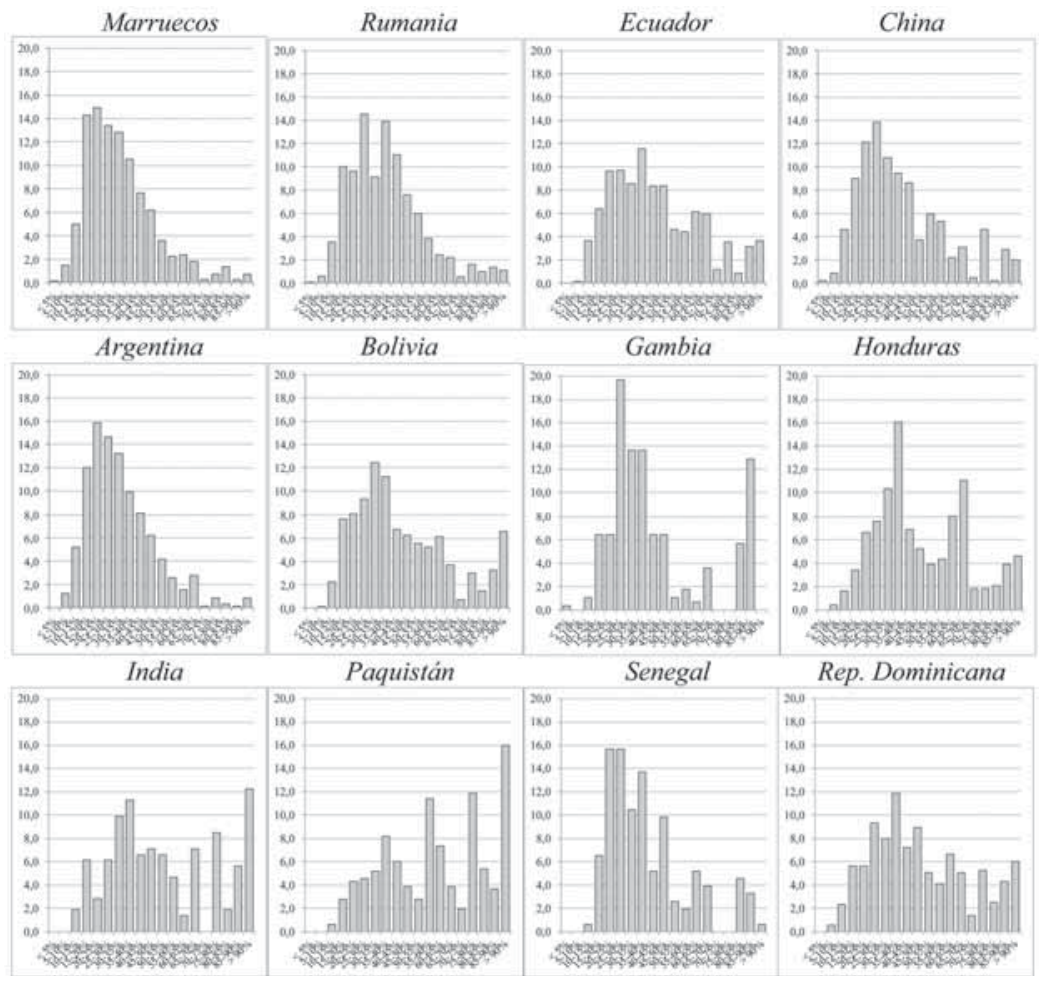

Fuente: datos del Departament d'Ensenyament. 
aportadas desde la nacionalidad, cuando unas nacionalidades siguen visibles mientras otras son invisibilizadas por su acceso a la nacionalidad española. Entre los doce orígenes examinados los niveles de concentración (ver figura 6) varían ostensiblemente, desde los casos de argentinos y rumanos, donde la concentración es poco significativa, a los de pakistaníes, en el polo opuesto. Observando la presencia en escuelas con menos del $20 \%$ de sus alumnos de origen inmigrante, destacaría el volumen de argentinos $(18,4 \%)$ y rumanos $(20,4 \%)$, mientras que apenas un 3,5\% de los pakistaníes pero también un 5,5\% de los hondureños se localizarían en tales escuelas. Si nos fijamos en el extremo contrario, y marcando un umbral del $50 \%$ de los alumnos, rumanos y argentinos son los que menos casos encontraríamos en esta situación (en ambos orígenes un 13,5\% de los alumnos), mientras que un $64,4 \%$ de los pakistaníes, o un $48 \%$ de los indios vivirían este elevado grado de concentración. Los alumnos hondureños $(41,6 \%)$ y los dominicanos $(40,3 \%)$ también experimentarían elevadas presencias en la concentración. En cambio, para los alumnos marroquíes esta sobrerrepresentación solo afecta al 20\% de los escolares.

Atendiendo a estos niveles de concentración se representa la relación entre origen y fracaso escolar (figura 7). En esta ocasión, y debido al menor número de casos con que se cuenta, se agrupan los datos en intervalos más amplios, del $20 \%$. Los resultados obtenidos no siempre son representativos según el sexo, debido a que en alguna de las categorías el número de escolares es muy reducido. Contando con estos impedimentos, los resultados alcanzados apuntan a la existencia de una elevada diversidad de situaciones. Desde casos como el de los alumnos de origen indio, donde se identifica una relación intensa entre concentración territorial y fracaso, a situaciones como la de los ecuatorianos, donde incluso la relación sería la inversa. Su interpretación se apoya en la composición diferencial del alumnado y la posición relativa de cada uno de los orígenes en relación al resto. De esta forma, se observa cómo en general los alumnos latinoamericanos mejoran sus resultados a medida que aumenta la concentración, ya que en estas circunstancias rentabilizarían su mayor conocimiento de la lengua en comparación a otros orígenes. En cambio, para el resto de situaciones, y en particular los asiáticos, el crecimiento de la concentración significa un crecimiento del fracaso, muchas veces en relación con una mayor presencia de la Primera Generación en las zonas de mayor concentración. 
FigURA 7

\section{RELACIÓN ENTRE FRACASO Y CONCENTRACIÓN ESCOLAR, CURSO 2015-2016}

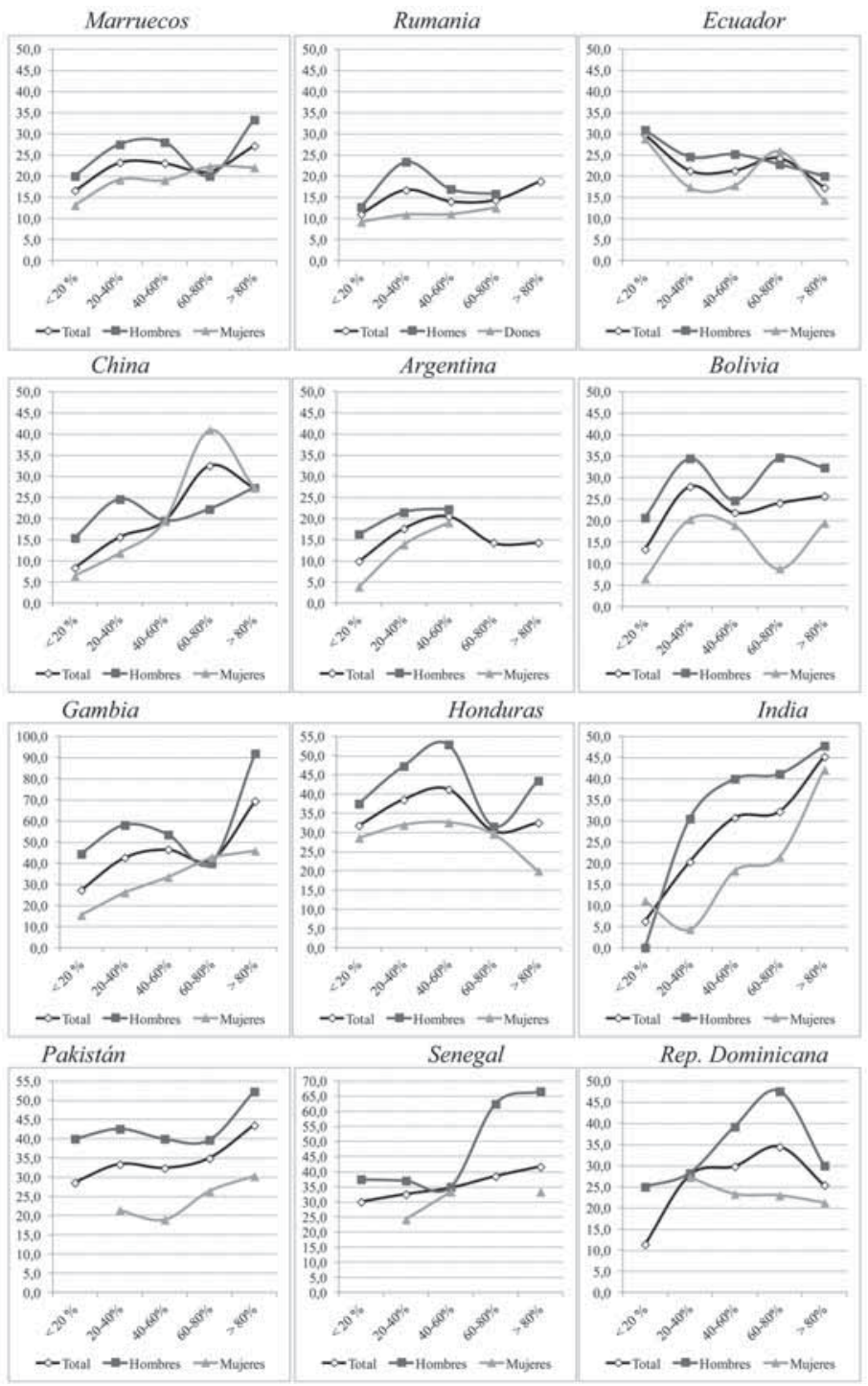

Fuente: datos del Departament d'Ensenyament. 
Para finalizar, se analiza el efecto de la concentración de un mismo origen sobre sus resultados, ya que en la bibliografía se relaciona este factor con un aumento del fracaso escolar (Schneeweis, 2015). El grado de concentración, como en el ejercicio anterior, se calcula teniendo en cuenta a todo el alumnado identificado con cada uno de estos orígenes, y solo se presentan resultados para los tres orígenes con un número de alumnos significativo (ver la figura 8). Para los marroquíes, se percibe un ligero aumento del fracaso con la concentración, visible especialmente cuando se supera el umbral del $20 \%$ de los alumnos. Por debajo de este valor no se puede considerar que exista relación alguna entre concentración y fracaso. Para los alumnos rumanos se constata un crecimiento del fracaso escolar entre los dos primeros niveles de concentración, aunque cuando estos mismos niveles aumentan la tendencia se invierte y en cambio se registran mejores resultados. En el tercer grupo de alumnos, los menores ecuatorianos, parece observarse también un ligero aumento del fracaso con la concentración, aunque por encima del $20 \%$ este aumento no continúa. En este análisis tampoco puede establecerse una relación directa entre el crecimiento de la concentración de un colectivo y la consecución del graduado escolar.

FIGURA 8

CONCENTRACIÓN SEGÚN ORIGEN Y FRACASO ESCOLAR, PRINCIPALES ORÍGENES, CURSO 2015-2016

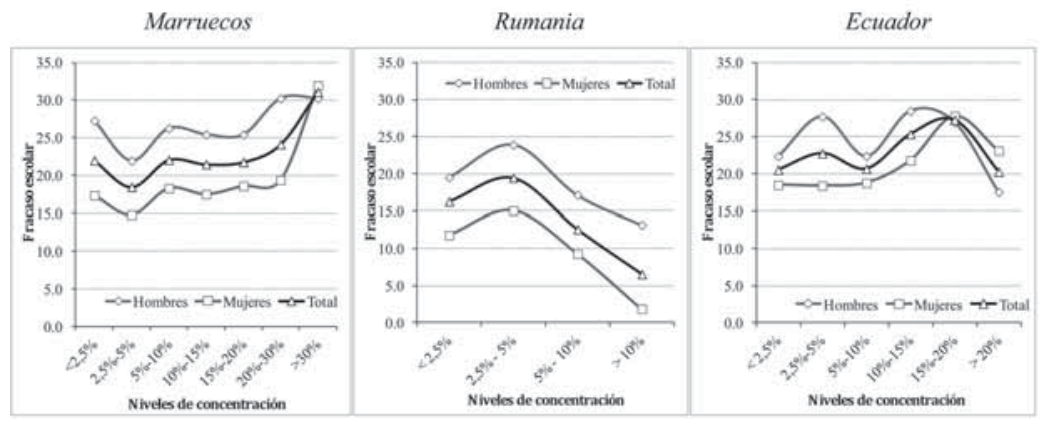

Fuente: datos del Departament d'Ensenyament. 


\section{CONCLUSIONES}

La composición por origen del alumnado de las escuelas catalanas ha conocido profundos cambios en los últimos años como consecuencia del intenso crecimiento migratorio producido en España a inicios de siglo XXI. Estos cambios seguirán siendo visibles y se podrán incrementar en los próximos años, en cuanto se incorporen plenamente a la escuela los descendientes de los inmigrantes, a los que debemos sumar los alumnos de nueva incorporación relacionados con un posible repunte de los flujos migratorios coincidiendo con ligeras mejoras económicas. En este sentido, el alumnado agrupado bajo la etiqueta de un único origen (por ejemplo, alumnado extranjero o inmigrante) se compone de individuos con trayectorias migratorias dispares, que si bien corresponden a estrategias migratorias relacionadas con orígenes y construcciones de género determinados, también se encuentran fuertemente condicionadas por la coyuntura económica. De esta forma, lo que a veces se lee precipitadamente como una "característica propia del origen", toma un carácter diferente si se analiza la composición del alumnado según su trayectoria migratoria. La complejidad depende también del territorio, que deberemos considerar como uno de los factores contextuales más importantes. A falta de conocer las características socioeconómicas de las familias (los datos disponibles no incorporan esta dimensión), se asume que la concentración y la segregación residencial y escolar de ciertos orígenes está traduciendo los condicionantes socioeconómicos de las diversas familias y hogares en las que viven estos alumnos.

En cuanto a los resultados alcanzados, debemos tener en cuenta que la forma de calcular el fracaso escolar, a partir de la obtención del graduado de ESO, puede que no sea el mejor instrumento de medida en relación a la concentración. En esta dirección podrían justificarse algunos resultados contraintuitivos, como el menor fracaso escolar relacionado con las concentraciones más intensas entre los latinoamericanos, y que debe advertirnos de la necesidad de emplear varias perspectivas en el análisis de los resultados escolares, y donde la información sobre competencias adquiridas sería fundamental.

En este trabajo nos preguntábamos directamente por el efecto de la concentración sobre los resultados escolares, como una de las consecuencias negativas de la desigual distribución del alumnado. Los resultados indican cómo este efecto es relativamente débil y 
más visible entre los alumnos autóctonos, resultados que coinciden plenamente con investigaciones anteriores. Esta situación se reproduce sea cual sea la óptica de análisis, desde la perspectiva de la nacionalidad (españoles/extranjeros), del país de nacimiento (España/ extranjero) o del estatus migratorio (autóctonos/resto situaciones). Estos resultados tienen una doble lectura. A pesar de que no exista un "efecto concentración" o de que éste sea débil, queda demostrado que en las escuelas con mayores índices de concentración, sea cual sea la estrategia de análisis de la misma, los resultados escolares son peores. Al mismo tiempo, el efecto negativo sobre los autóctonos reincide en indicar un posible efecto de selección, ya que algunas escuelas son evitadas por parte del alumnado autóctono, permaneciendo en ellas los alumnos con situaciones más desfavorables. Aunque no se ha dispuesto de datos que informen de las características socioeconómicas de los alumnos, este fenómeno de White flight mostrará, con toda seguridad, un importante sesgo en función del nivel socioeconómico de las familias. En consecuencia, a mayor concentración, mayor fracaso escolar, por un efecto de composición del alumnado. Por otro lado, entre los alumnos inmigrados (también extranjeros o para las categorías de estatus a excepción de la Generación 2,5) la concentración sólo es negativa en niveles muy elevados. Esto coincide también con estudios anteriores, aunque al utilizar una medida de concentración donde se incorporan todos los alumnos de ascendencia inmigrante, los efectos se producen en umbrales superiores a otras investigaciones. Contrastando con estos resultados, es significativo cómo se alcanzan buenos rendimientos escolares cuando esta concentración es muy baja. Finalmente, la elevada diversidad de situaciones identificadas en el análisis según orígenes sugiere que la relación entre concentración y fracaso escolar no puede ser abordada desde políticas generalistas y únicas.

\section{BIBLIOGRAFÍA}

Achebak, H., Bayona, J. y Domingo, A. (2017). Evolución y pautas geográficas de la segregación residencial de los marroquíes en España. Estudios geográficos, 283: 417-443.

Alegre, M. A. (2017). Polítiques de tria i assignació d'escola: quins efectes tenen sobre la segregació escolar? Fundació Jaume Bofill / Ivàlua. 
Alegre, M. A., Benito, R. y González, I. (2008). Procesos de segregación y polarización escolar: la incidencia de las políticas de zonificación escolar. Profesorado. Revista de curriculum y formación del profesorado, 12(2).

Aparicio, R. y Portes, A. (2014). Crecer en España. La integración de los hijos de inmigrantes. Barcelona: Obra Social La Caixa. Colección Estudios Sociales, 38.

Bayona, J., Domingo, A. y Menacho, T. (en prensa). Trayectorias migratorias y fracaso escolar de los alumnos inmigrados y descendientes de migrantes en Cataluña. RIS, Revista Internacional de Sociología

Bayona, J. y López-Gay, A. (2011). Concentración, segregación y movilidad residencial de los extranjeros en Barcelona. Documents d'Anàlisi Geogràfica, 57 (3), 381-412

Benito, R. y González, I. (2007). Processos de segregació escolar a Catalunya. Col-lecció Polítiques, 59, Fundació Jaume Bofill.

Blanco, I. y Nel.lo, O. (2018) (eds.). Barrios y crisis. Crisis económica, segregación urbana e innovación social en Cataluña. Tirant lo Blanch, Valencia.

Bonal, X. (2015). Equitat $i$ resultats educatius a Catalunya. Una mirada a partir de PISA 2012. Fundació Jaume Bofill.

Bonal, X. (2012). Municipis contra la segregació escolar. Sis experiències de política educativa local. Col-lecció polítiques 78. Fundació Jaume Bofill.

Bonal, X. y Zancajo, A (2018). School segregation in the spanish quasimarket education system: local dynamics and policy absences. En Bonal, X. y Bellei, C. (eds.). Understanding school segregation: patterns, causes and consequences of spatial inequalities in education. Bloomsbury publishing, p. 201-220.

Bolívar, A. y López-Calvo, L. (2009). Las grandes cifras del fracaso y los riesgos de exclusión educativa. Profesorado, revista de currículum y formación de profesorado, 13(3), 51-78.

Burgess, E. W. (1928). Residential segregation in american cities. The annals of the american academy of political and social science, 140 (1), 105-115.

Calero, J. y Escardíbul, J.O. (2016). Proceso educativo y resultados del alumnado nativo y de origen inmigrante en España. Un anàlisis basado en PISA-2012. Estudios de economía aplicada, 34-2, 413-438.

Carrasco, S. (2011). Segregación escolar e inmigración: repensando planteamientos y alternativas. En García-Castaño, F.J. y Carrasco, S. (eds.). Población inmigrante y escuela: conocimientos y saberes de investigación. Ministerio de educación. Colección Estudios Creade, 8, 269-288.

Carrasco, S., Pàmies, J., Ponferrada, M., Ballestín, B., Bertran, M. (2007). Segregación escolar e inmigración en Cataluña: aproximaciones etnográficas. Emigra working papers, n. 126.

Cebolla-Boado, H. y Garrido, L. (2011). The impact of immigrant concentration in spanish schools: school, class, and composition effects. European sociological review, 27(5), 606-623. 
Choi, A. y Calero, J. (2012). Rendimiento académico y titularidad de centro en españa. Profesorado. Revista de currículum y formación de profesorado, 16(3), 31-57.

Coleman, J. S., Kelly, S. D., Moore, J. A. (1975). Trends in school segregation, 1968-73. Washington, The Urban Institute.

Departament d'Ensenyament (2013). Ofensiva de país a favor de l'èxit escolar. Pla per a la reducció del fracàs escolar a Catalunya, 2012-2018. Generalitat de Catalunya.

Domingo, A. y Bayona, J. (2016). Panoràmica de la immigració a Catalunya. En Pinyol-Jiménez, G. (coord.). Informe sobre la integració de les persones immigrades a Catalunya 2015, Secretaria d'Igualtat, Migracions i Ciutadania, Generalitat de Catalunya, p. 10-45.

Galeano, J., Sabater, A., y Domingo, A. (2015). Formation and evolution of ethnic enclaves in catalonia before and during the economic crisis. Catalan Social Sciences Review, n. 5, p. 59-86.

Garrido, L. y Cebolla-Boado, H. (2010). Rendimiento educativo y concentración de inmigrantes en las escuelas españolas: PISA-2006. Presupuesto y Gasto público, 61/210, 159-176.

González-Ferrer, A. y Cebolla-Boado, H (2018). Los hijos de la inmigración en España: valores, aspiraciones y resultados. En Blanco, A. et al. (coord.) Informe España 2018. Madrid: Universidad Pontificia Comillas, Cátedra J.M. Martín Patino, p. 111-163.

Ham, M. van et al. (ed.) (2012) Neighbourhood effects research: new perspectives. London: Springer.

Hardoy, I., Mastekaasa, A. y Schøne, P (2018). Immigrant concentration and student outcomes in upper secondary schools: norwegian evidence. European societies, 20(2), 301-321.

López-Falcón, D. y Bayona, J. (2012). Segregación escolar y residencial en Barcelona: del boom migratorio al asentamiento. En García-Castaño, F.J. y Olmos, A. (ed.). Segregaciones y construcción de la diferencia en la escuela, Editorial Trotta, 21-42.

Massey, D. S. y Denton, N. (1988). The dimensions of residential segregation, Social Forces, 67(2), 281-315.

Murillo, F. J. y Martínez-Garrido, C. (2018). Magnitud de la segregación escolar por nivel socioeconómico en España y sus CCAA y comparación con los países de la Unión Europea. Rase, 11(1), 37-58.

Murillo, F. J., Martínez-Garrido, C. y Belavi, G. (2017). Segregación escolar por origen nacional en España. Obets, Revista de Ciencias Sociales, 12(2): 395-423.

Nel.lo, O. (2018). Segregació residencial, gentrificació urbana i dret a la ciutat: una lectura des de Barcelona. Papers, 60, 48-61.

Portes, A.; Aparicio, R. y Haller, W. (2016). Spanish legacies: the coming of age of the second generation. Oakland, California: University of California Press. 
Rubiales, M. Patrones socioterritoriales de las clases altas en las regiones metropolitanas de Barcelona y Madrid, 2001-2015. Tesis doctoral, 2017.

Rujas, J. (2015). Sociología del "fracaso escolar" en España. Construcción y gestión de un problema social. Tesis doctoral, Universidad Complutense de Madrid.

Rumbaut, R. G. (2004). Ages, life stages, and generational cohorts: decomposing the immigrant first and second generations in the United States. International Migration Review, 38(2): 1160-1205.

Sánchez-Hugalde, A (2009). La segregació escolar dels immigrants a Catalunya. Quaderns d'avaluació, 13, 1-22.

Sarasa, S., Porcel, S. y Navarro-Varas, L. (2013). L'impacte social de la crisi a l'àrea metropolitana de Barcelona i a Catalunya. Papers. Regió Metropolitana de Barcelona, 56, 10-88.

Schneeweis, N (2015). Immigrant concentration in schools: consequences for native and migrant students. Labour Economics, 35, 63-76.

Síndic de Greuges (2008). La segregació escolar a Catalunya. Informe extraordinari. Síndic de Greuges de Catalunya.

Síndic de Greuges (2016). La segregació escolar a Catalunya (I): la gestió del procés d'admissió d'alumnat. Juliol 2016, Síndic de Greuges de Catalunya, 2016.

Subirats, M. (2015). La complexa trajectòria de l'educació. En Giner, S. y Homs, O. (dir.) Raó de Catalunya. La societat catalana al segle xxi, p. 287304. Barcelona: Institut d'Estudis Catalans.

Slater, T. (2015). Territorial stigmatization: symbolic defamation and the contemporary metropolis. En Hannigan, J. y Richards, G. (eds.) The handbook of new urban studies. London: Sage publications.

Tarabini, A., Montes, A. y Parcerisa, Ll. (2018). Les aliances Magnet: innovació per combatre la segregació escolar. Fundació Jaume Bofill, Col-lecció Informes Breus, 68. 